\title{
Research and Modelling of Surface Roughness, Cutting Forces and I-kaz Coefficients for S42C in Turning using Response Surface Methodology
}

\author{
R. Samin, M. Z. Nuawi, J. A. Ghani, S. M. Haris
}

\begin{abstract}
This paper presents the optimization in machining processes on the cutting parameters for the $S 45 C$ in turning process using the response surface method (RSM). The experimental work conducted investigates the influence of cutting parameters on statistical analysis of signals and surface quality. The paper also presents a statistical analysis of signal processing. The cutting force was measured during machining using the Kistler 9129AA dynamometer to monitor the force signals and the data was analyzed using the I-kazTM method of statistical analysis. This statistical analysis was used to assess the effect of force signals during the machining process. The RSM models for $R a$ and $R z$, and I-kaz coefficients $(Z \square)$ have been developed with ANOVA and multiple regression equations. The models also were compared and validated with the predicted and measured of $R a$ and $R z$ values, and I-kaz coefficients. The optimal configuration of cutting parameters was observed at 200 $\mathrm{m} / \mathrm{min}, 0.1 \mathrm{~mm} / \mathrm{rev}$ and $0.521 \mathrm{~mm}$ with desirability of $95.9 \%$. It is observed that the models developed are suggested to be utilized for predicting surface roughness values and I-kaz coefficients for the machining of S45C steel.
\end{abstract}

Keywords: Cutting force, I-kazTM, response surface methodology, surface quality, turning.

\section{INTRODUCTION}

Nowadays, machining processes involve measuring, modelling, prediction, and optimization to produce products that require very high surface quality. Research in machining process still presents a challenge, because cutting parameters or cutting processes must be considered in order to determine the optimal process of machining conditions. In the turning processes, the cutting parameters commonly identified are materials and cutting tools. Meanwhile, the cutting processes are influenced by the tool condition, chatter, surface finish, dimensional precision, chip formation and cooling method. In order to model the machining, some researchers apply modelling approaches in their research. In [1] created the homotopy perturbation model for chatter prediction in turning using spindle speed variation technique and a mathematical model which it is showed good

Revised Manuscript Received on October 23, 2019.

R. Samin, Department of Mechanical and Materials Engineering, Faculty of Engineering and Built Environment, Universiti Kebangsaan Malaysia, Bangi, Selangor, Malaysia \& Department of Mechanical and Manufacturing Engineering, Faculty of Engineering, Universiti Putra Malaysia, Serdang, Selangor, Malaysia. (Email: zali@upm.edu.my)

M. Z. Nuawi, Department of Mechanical and Materials Engineering, Faculty of Engineering and Built Environment, Universiti Kebangsaan Malaysia, Bangi, Selangor, Malaysia.

S. M. Haris, Department of Mechanical and Materials Engineering, Faculty of Engineering and Built Environment, Universiti Kebangsaan Malaysia, Bangi, Selangor, Malaysia.

J. A. Ghani, Department of Mechanical and Materials Engineering, Faculty of Engineering and Built Environment, Universiti Kebangsaan Malaysia, Bangi, Selangor, Malaysia. agreement with experimental cutting tests. In [2] used an energy based modelling for prediction of process damping in milling and turning. Their results were useful for chatter stability analysis with low cutting speeds. In [3] studied the Kelvin-Voigt model that used to minimize the tool overshoot using computational objective function that influence the machining process, surface finish and tool life issues. In [4] mentioned that an understanding of measurement uncertainty of the model is required for a machine tool to produce the product quality and this is influenced by the model accuracy from the cutting tool that is utilized to post-process the CAD model.

Statistical methods were extensively used in machining for finding out the significance of cutting processes and parameters based on the modelling, prediction and optimization. In [5] carried out the response surface methodology which depended on faced centred composite design and ANOVA with mathematical modelling of surface roughness and flank wear for Monel-400 workpiece in turning process. From the regression equation, maximum errors between predicted and experimental measures obtained were $7 \%$ for surface roughness and $13 \%$ for flank wear. In [6] concluded that, compared to cutting speed and feed rate, the depth of cut has the largest influence on force signals. They used the AISI 52100 workpiece through RSM and ANNOVA with consideration for the optimization goals between surface roughness and cutting force values in tangential, thrust and feed forces. The goals of this research were to evaluate the correlation between surface roughness, cutting forces and statistical method $\mathrm{I}_{-\mathrm{Kaz}^{\mathrm{TM}}}$ to cutting parameters and then to determine the optimization model by using response surface methodology.

\section{METHODOLOGY}

\section{A. Material and Workpiece}

The experimental works in this paper were tested on a round bar work piece of medium carbon steel S45C with a diameter of $75 \mathrm{~mm}$ and length of $250 \mathrm{~mm}$. Mild steel S45C is a medium carbon steel according to the Japanese Industrial Standard (JIS). These steel pieces have high weldability and machinability, and they can be subjected to various heat treatments. JIS S45C is medium strength steel and most commonly used in mechanical parts because its cost is comparatively small and it offers material properties suitable for many applications. The original Hardness

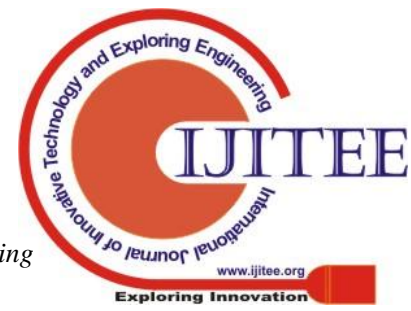




\section{RESEARCH AND MODELLING OF SURFACE ROUGHNESS, CUTTING FORCES AND I-KAZ COEFFICIENTS FOR S42C IN TURNING USING RESPONSE SURFACE METHODOLOGY}

Rockwell B is 59 HRB. This workpiece has nominal material properties of 0.42 per cent Carbon, 98.51 per cent to 98.98 per cent Iron, 0.15 per cent to 0.35 per cent Silicon, 0.6 per cent to 0.9 per cent Maganese, 0.03 per cent Plumbum and 0.035 per cent Sulphur. The end of the supported by a tailstock. In [7] classified the ratio of length to diameter used is $3: 1$ to $6: 1$. The length to diameter for this work piece in this paper is 3.33:1, which falls within the acceptable range of the ratio. The range of machine parameters was chosen during the investigation on the recommendation of the manufacturer of the cutting tool.

\section{B. Experimental Procedure}

Machining experiments were conducted to investigate the impact of the cutting parameters on the workpiece's surface roughness and I-kaz ${ }^{\mathrm{TM}_{\mathrm{i}}}$ s signal processing. The experiment was performed on the turning process using a computer numerical control $(\mathrm{CNC})$ lathe machine. The lathe machine (Mazak SQT 200MY) was used for performing the machining operation. The cutting tool materials were selected based on the workpiece materials to be cut. Based on the recommendations of the cutting tool manual and the cutting manual, cutting tool inserts of coated carbide were used for turning of mild steel S45C material.

Table I shows that the cutting parameters in this experiment is $200-300 \mathrm{~m} / \mathrm{min}$ for cutting speed, $0.5-1.5 \mathrm{~mm}$ for the depth of cut and $0.1-0.2 \mathrm{~mm} / \mathrm{rev}$ for the feed rate. The machine tool was used the tool holder type ECLNR2020K12 carbide by Chain designed with ISO 9001:2015 to hold the CVD-coated carbide insert type CNMG12044NGU AC2000 by Sumitomo.

Table- I: Factor and response levels for the turning process

\begin{tabular}{|c|c|c|c|c|c|}
\hline \multirow{2}{*}{ Level Factors } & & Unit & \multicolumn{3}{|c|}{ Responses } \\
\cline { 2 - 6 } & & & $\boldsymbol{1}$ & $\mathbf{2}$ & $\mathbf{3}$ \\
\hline Cutting speed & $V c$ & $\mathrm{~m} / \mathrm{min}$ & 200 & 250 & 300 \\
\hline Feed rate & $f$ & $\mathrm{~mm} / \mathrm{rev}$ & 0.10 & 0.15 & 0.20 \\
\hline Depth of cut & $d$ & $\mathrm{~mm}$ & 0.50 & 1.00 & 1.50 \\
\hline
\end{tabular}

The turning experiment conducted refers to the ISO3685 conducted without the use of cutting fluid for the S45C.

This paper uses the arithmetic average of the roughness profile, $R a$ and mean depth of profile surface roughness, $R z$ values. On the machined workpiece, the surface roughness, $R a$ and $R z$ were measured using the MarSurf PS1 gauge. The $R a$ and $R z$ values are the commonly used roughness parameter and most appropriate for observing the surface quality of the machining processes [8]-[11]. The force signals were measured using a dynamometer by Kistler type 9129AA and placed on the tool frame, measuring the force signals in the direction of tangential and cutting (to the moving workpiece), feed and also in the direction of radial or thrust.

\section{Statistical Analysis Method}

The I-kaz coefficient, $Z^{\infty}$ was determined by statistical moments based on average value, standard deviation, root mean square and kurtosis. The first central moment is the expectation value for mean, which is the central location of workpiece is clamped in a chuck and the other end is standard (ISO 3685, 1993). The cutting process was

a distribution and is given in (1). In practice it is estimated by the average or the mean deviation from the mean as shown in (2). For the chosen workpiece and tool material combination, Wang et al. (2014) used average forces for $X$ and $Y$ directions [12].

$$
\begin{aligned}
& \mu=\mathrm{E}(\bar{x})=\frac{1}{n} \sum_{i=1}^{n} x_{i} \\
& \bar{x}=\frac{1}{n} \sum_{i=1}^{n}\left(x_{i}-\mu\right)
\end{aligned}
$$

Since the first moment data is for mean, $\mu$ the second statistical moment is for variance (var) and the standard deviation, $\sigma$. The average deviation, $\left(x_{i}-\mu\right)$ is a more robust analysis tool of the width of the peak appearance. In (3) shows the variance, it provides a measure of the data spread and it is frequently used interchangeably with its positive square root, defining the standard deviation in (4).

$$
\begin{aligned}
& \operatorname{var}=\frac{1}{n} \sum_{i=1}^{n}\left(x_{i}-\mu\right)^{2} \\
& \sigma=\sqrt{\operatorname{var}}=\frac{1}{n} \sum_{i=1}^{n}\left(x_{i}-\mu\right)
\end{aligned}
$$

In (5) shows the third central moment, skewness $(S)$ which identifies a distribution's degree of asymmetry around its mean. Wang et al. (2017) used skew, mean and kurtosis to assess surface roughness and used wavelet packet transform to extract surface texture [13]. They found that the mean, skewness and kurtosis values increased with the rise in noise, meaning that these statistical moments are influenced by noise much stronger than surface roughness values. The skewness is a non-dimensional quantity.

$$
S=\frac{1}{n} \sum_{i=1}^{n}\left(\frac{x_{i}-\mu}{\sigma}\right)^{3}
$$

The fourth-order statistical moment is kurtosis $(K)$. It measures the relative peakness or flatness of a distribution. Platykurtic is called flat-looking distributions, while peaked distributions are called leptokurtic distributions. In the I$\mathrm{kaz}^{\mathrm{TM}}$ definition, the Gaussian distribution data for kurtosis is about 3.0 and the value of -3 has been ignored to create the zero value for the normal distribution as shown in (6). Higher kurtosis values show a Gaussian distribution with more extreme values. The Kurtosis is also non-dimensional quantity and used in engineering to detect symptoms of fault owing to its sensitivity to elevated amplitude occurrences.

$$
K=\frac{1}{n} \sum_{i=1}^{n}\left(\frac{x_{i}-\mu}{\sigma}\right)^{4}
$$

Traditionally, sample data processes by root mean square and kurtosis were utilized as a measure of the impulsivity and energy of the signal for signal processing applications [14]. In [15] stated that measures of skew and kurtosis are often utilized to describe the distribution shape. They found that with the larger sample sizes, the mean-square errors for skewness and kurtosis decreased, and with small sample sizes, error increased.

The study shows that the use of kurtosis is significant in the machining process because normally larger samples are 
used. Kurtosis is highly sensitive to raw data spikiness. A signal processing approach, I-kaz ${ }^{\mathrm{TM}}$ is based on the fourth order statistical moment or kurtosis. In this paper, the statistical analysis method developed by [16] was used. The method was an alternative statistical analysis for Z-filter. The integrated kurtosis-based algorithm was applied to evaluate the degree of dynamic signal analysis for scattering of the raw signal data with respect to the centroid. In this method the Z-notch filter was used due to the fact that the filter efficiently extracted the component of noise from the measured data of the machining signals [17]. The centroid is accessed by decomposition from the average position of all the points of the all data signal.

Fig. 1 shows the I-kaz ${ }^{\mathrm{TM}}$ decomposition procedure. From the signal data distribution, raw time domain data is processed at three different frequency ranges as low $(L F)=$ $0-0.25 f_{\max }$, high $(H F)=0.25 f_{\max }-0.5 f_{\max }$ and very high $(V F)=0.5 f_{\max }-f_{\max }$ frequencies. The selection of the frequency ranges takes into account the Daubechies concept with second order in the process of decomposition of signal on the raw signal, $f_{\max }=f_{\mathrm{s}} / 2.56$, where, $f_{\max }$ is maximum frequency span, $f_{\mathrm{s}}$ is the sampling frequency and 2.56 is the Nyquist number. The I-kaz ${ }^{\mathrm{TM}}$ technique generates a graphical representation of 3 dimensions by scattering the signal decomposition for each frequency distribution, low, high and very high bands. The standard deviation provides the mean deviation, $\left(x_{i}-\mu\right)$ between the immediate data, $x_{i}$ and mean value, $u$ as shown in (7):

$$
\begin{gathered}
\sigma_{L F}^{2}=\frac{1}{n} \sum_{i=1}^{n}\left(x_{L F, i}-u_{L F}\right)^{2} \\
\sigma_{H F}^{2}=\frac{1}{n} \sum_{i=1}^{n}\left(x_{H F, i}-u_{H F}\right)^{2} \\
\sigma_{V F}^{2}=\frac{1}{n} \sum_{i=1}^{n}\left(x_{V F, i}-u_{V F}\right)^{2}
\end{gathered}
$$

where $\sigma_{L F}^{2}, \sigma_{H F}^{2}$ and $\sigma_{V F}^{2}$ are the variances, $x_{L F, i}$, $x_{H F, i}$ and $x_{V F, i}$ are $i$-sample time of the mean data range, $\mu_{L F}, \mu_{H F}$ and $\mu_{V F}$, while $n$ is the data sizes. In (7) shows the sum of the variances can be expressed as the sum of levels of intensity.

$$
\begin{aligned}
& Z^{\infty}=\sqrt{\sigma_{L F}^{4}+\sigma_{H F}^{4}+\sigma_{V F}^{4}} \\
& Z^{\infty}=\sqrt{\frac{\sum_{i}^{N}\left(x_{L F, i}-u_{L F}\right)^{4}}{n^{2}}}+\sqrt{\frac{\sum_{i}^{N}\left(x_{H F, i}-u_{H F}\right)^{4}}{n^{2}}}+ \\
& \sqrt{\frac{\sum_{i}^{N}\left(x_{H F, i}-u_{H F}\right)^{4}}{n^{2}}} \\
& Z^{\infty}=\frac{1}{n} \sqrt{K_{L F} s_{L F}^{4}+K_{H F} s_{H F}^{4}+K_{V F} s_{V F}^{4}}
\end{aligned}
$$

It is possible to simplify the I-kaz coefficient in (7) and (8) is the sum of the root mean square of the standard deviation, $\sigma$ and the kurtosis, $K$ from the measured data of force signals, $K_{L F}, K_{H F}$ and $K_{V F}$ are the signal kurtosis and $s_{L F}^{2}, \quad s_{H F}^{2}$ and $s_{V F}^{2}$ are $L F, H F$ and $V F$ ranges for standard deviation respectively. In (9) is used to help display statistical signal analysis in three-dimensional graphical representation using the $\mathrm{I}-\mathrm{kaz}^{\mathrm{TM}}$ method. In the meantime, the I-kaz coefficient is determined in (10). The stationary dynamometer provides the force signals in three component measurement directions $F_{X}$ for $X$-direction, $F_{Y}$ for $Y$ direction and $F_{Z}$ for $Z$-direction, for measuring forces during the cutting process for radial, feed and cutting forces. The radial force moves the tool out of the machine. The cutting forces, force the cutting tool to turn and the feed or thrust force move it in the direction of the feed. Comparing the three forces, the magnitude of cutting force is the most important criteria to quantify the machinability of a material Nevertheless, in this paper the investigation of the statistical signal processing was considered on three force signals for all directions to seek the effect of each force signal on the surface roughness values.

\section{Response Surface Methodology}

A statistical approach using design of experiment is among the effective ways to analyze the influence of any input and process factors on their output responses. Some researchers have used different DOE approach for optimization in machining processes. In this paper, response surface methodology (RSM) by Design-Expert v.11 was used for optimizing because of the problems in the choice of cutting parameters based on modeling and assessment, where the output parameters are influenced by several parameters therefore creating a need to minimize the input parameters [18]. In [5] used RSM with factors as input parameters and response as output parameters for performing and modelling the relationship between them. They studied the optimization with four input factor parameters (workpiece temperature, depth of cut, cutting speed and feed rate) and two response parameters (tool wear and surface roughness) using the central composite design (CCD) in RSM and found that the cutting speed was the parameter that most affected surface roughness, next to the temperature for flank wear. Other researchers also used the optimization approach by RSM for measuring the optimum cutting parameters with output response parameters other than surface roughness and tool wear, such as chatter and wavelet transform [19], power, cutting force and specific cutting force [20], surface roughness, thrust, feed and tangential forces, and tool life, cutting forces [21]. The central composite rotatable design (CCRD) with 3 numeric factors and 5 responses, together with full type, 14 noncenter points and 6 center points was used to (8un 20 experiments and the factorial portion of the design, composed of points, is generally presented.

In (13) and (14) show the relationship between the input and output parameters [5].

$$
\begin{aligned}
& Y=F\left(\left(V_{c}\right),(f),(d)\right)+\text { Error } \\
& Y=c_{0}+\sum_{i}^{3} c_{i} x_{i}+\sum_{i}^{3} c_{i i} x_{i}+\sum_{i<j}^{3} c_{i j} x_{i} x_{j}
\end{aligned}
$$

where, $Y$ is a response in quadratic multiple polynomial regression, Error is a residual error from the experimental errors, $V_{c}, f$ and $d$ are cutting parameters for turning in a function, $c_{o}$ is the polynomial constant, $c_{i}, c_{i i}$, and $c_{i j}$ are the polynomial coefficients, $\mathrm{xi}$ and $x_{j}$ are the input parameters.

Published By: Blue Eyes Intelligence Engineering 


\section{RESEARCH AND MODELLING OF SURFACE ROUGHNESS, CUTTING FORCES AND I-KAZ COEFFICIENTS FOR S42C IN TURNING USING RESPONSE SURFACE METHODOLOGY}

\section{RESULTS AND ANALYSIS}

In this paper, the I-kaz coefficients were obtained from the cutting force in the time domain as shown in Fig. 1. The cutting forces for $X$-, $Y$ - and $Z$-directions were executed before and after the cutting processes. Fig. 2 shows the measured cutting force signals and Table II shows the measured values of the surface roughness from the experimental work. Fig. 3 shows the measured I-kaz coefficient and graph in $3 \mathrm{D}$ representation. The highest force value obtained was $0.3037 \mathrm{kN}$ at $Y$-direction for Experimental run 2. The surface roughness values were obtained in the range of $0.88-1.66 \mu \mathrm{m}$ for $R a$ and 5.45-9.07 $\mu \mathrm{m}$ for $R z$. Meanwhile, the I-kaz coefficients were obtained in the range of $3.8607 \mathrm{E}-09-5.3592 \mathrm{E}-08$ for $Z_{X}^{\infty}$, 9.8487E-09 - 1.0940E-07 for $Z_{Y}^{\infty}$ and 2.4236E-09 4.9783E-08 for $Z_{Z}^{\infty}$.

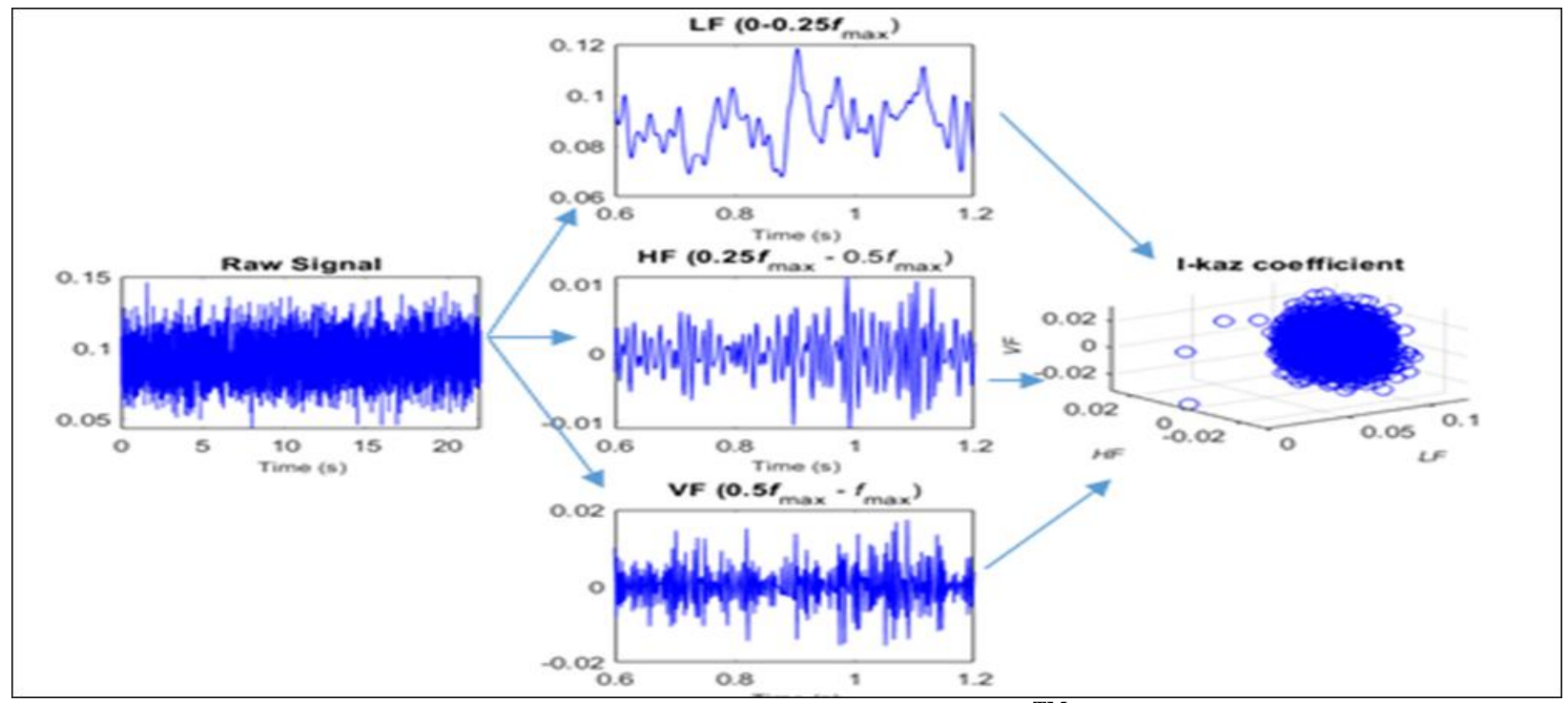

Fig. 1. Signal decomposition process for I-kaz ${ }^{\mathrm{TM}}$ method

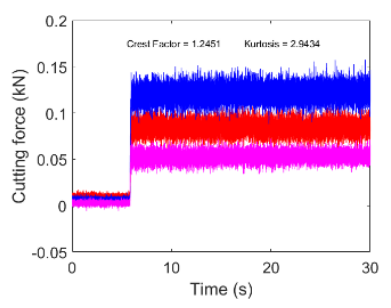

Run 1

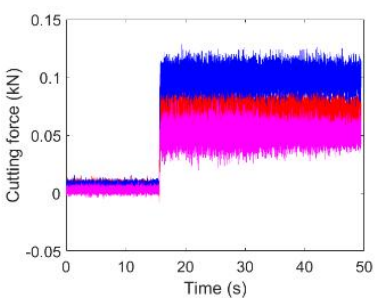

Run 5

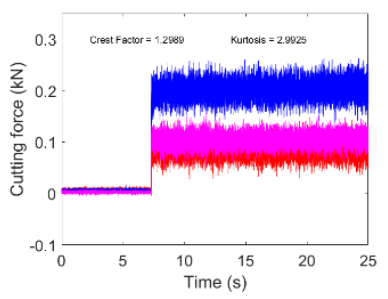

Run 9

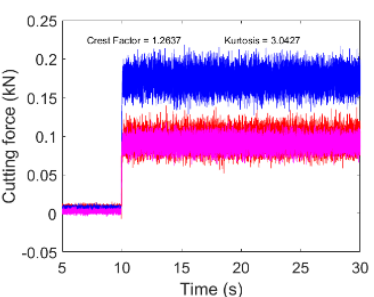

Run 2

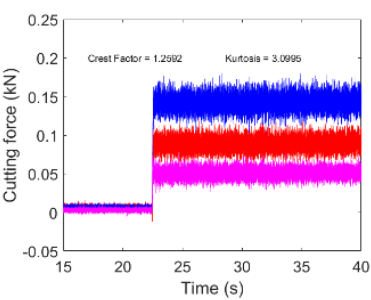

Run 6

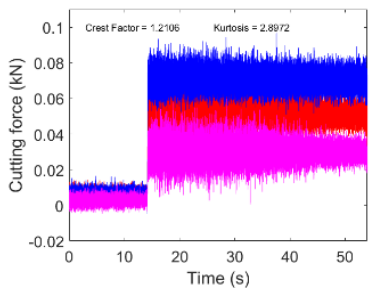

Run 10

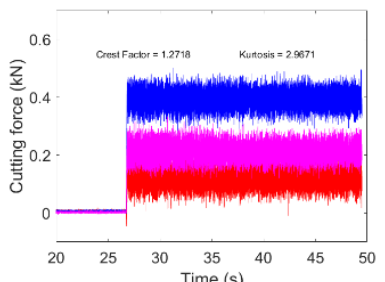

Run 3

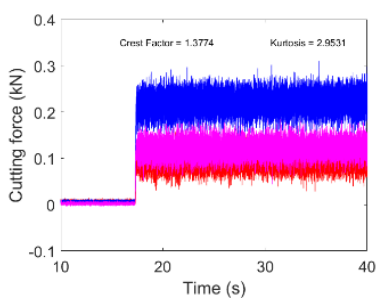

Run 7

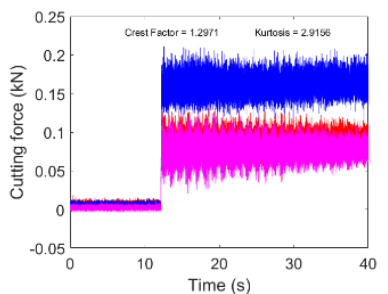

Run 11

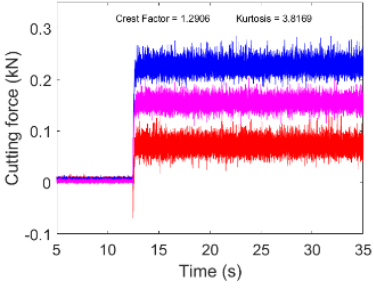

Run 4

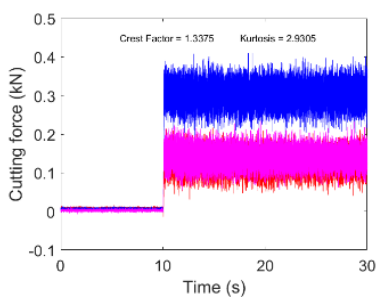

Run 8

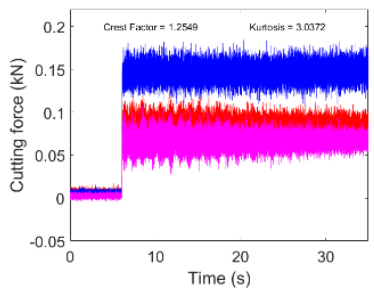

Run 12 


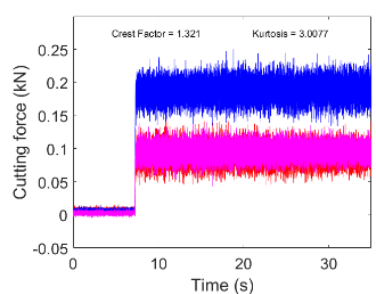

Run 13

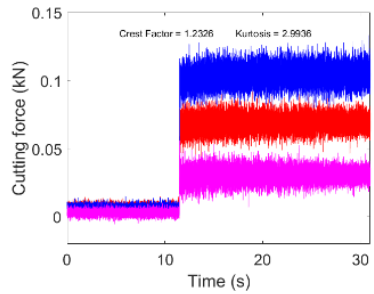

Run 17

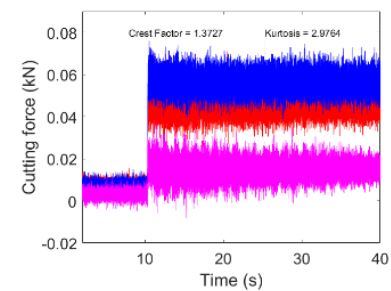

Run 14

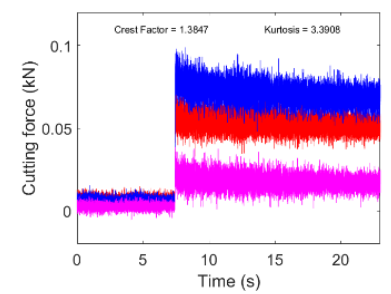

Run 18

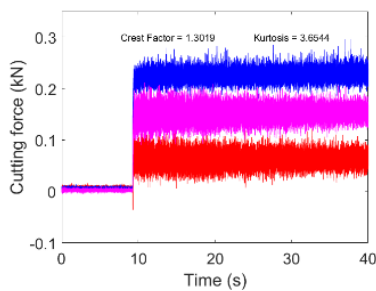

Run 15

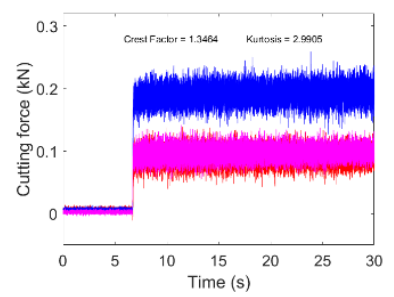

Run 19

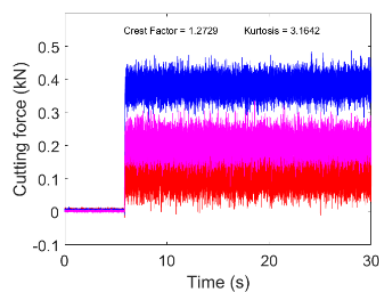

Run 16

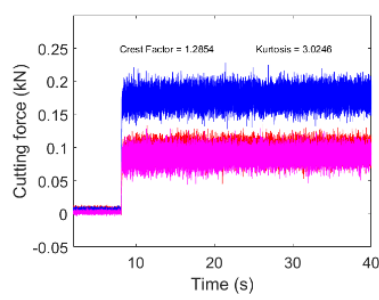

Run 20

Fig. 2. Cutting forces (X-, Y- and Z-directions) for all experimental runs
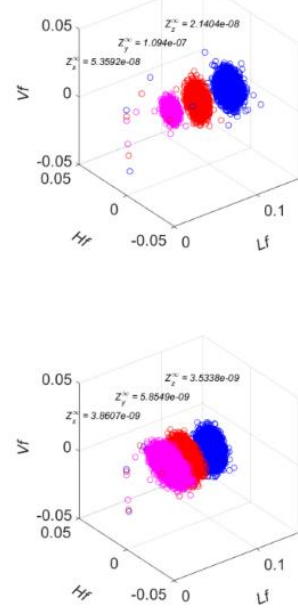

Run 5

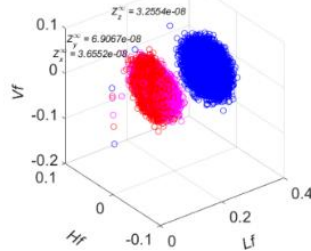

Run 9

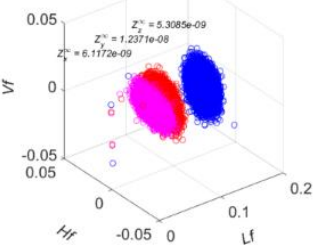

Run 13

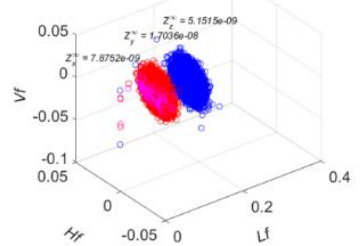

Run 1

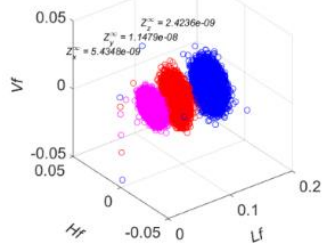

Run 6

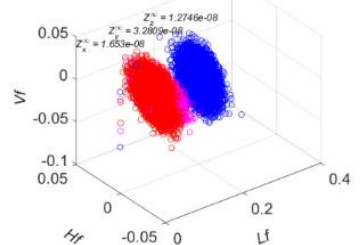

Run 10

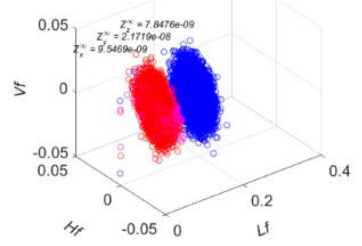

Run 14

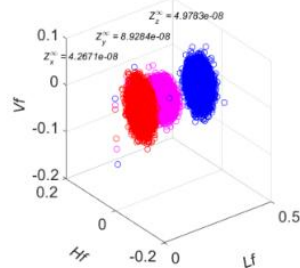

Run 2

Run 3

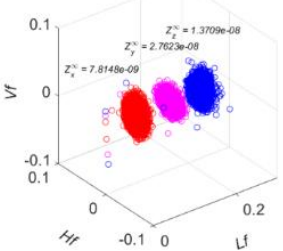

Run 4

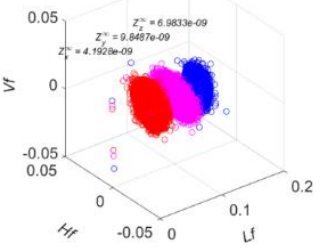

Run 7

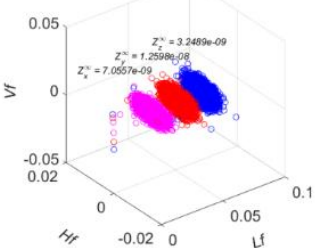

Run 11

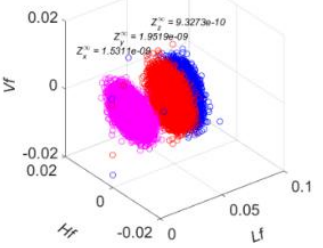

Run 15

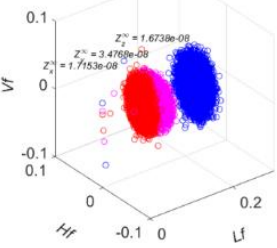

Run 8

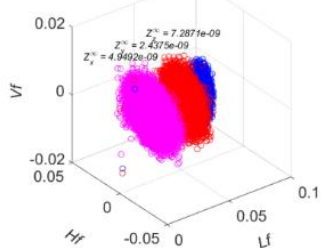

Run 12

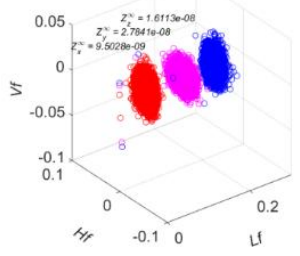

Run 16

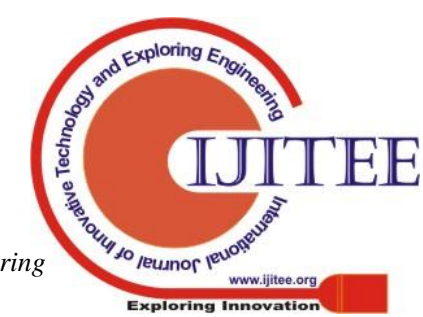




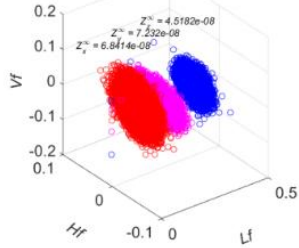

Run 17

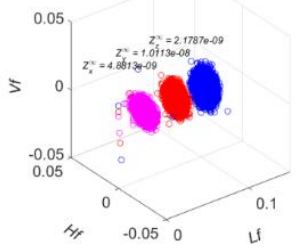

Run 18

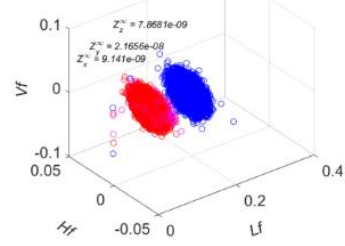

Run 19

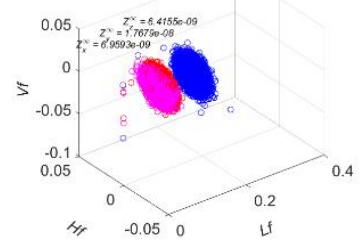

Run 20

Fig. 3. Measured I-kaz coefficient and graph in 3D representation

Table- II: Experimental results for surface roughness parameters and I-kaz ${ }^{\mathrm{TM}}$ coefficients

\begin{tabular}{|c|c|c|c|c|c|c|c|c|}
\hline \multirow{2}{*}{$\begin{array}{c}\text { Exp } \\
\text { Run } \\
\text { No. }\end{array}$} & \multicolumn{3}{|c|}{ Factors } & \multicolumn{5}{|c|}{ Responses } \\
\hline & $\begin{array}{c}V c \\
(\mathrm{~m} / \mathrm{min})\end{array}$ & $\begin{array}{c}f \\
(\mathrm{~mm} / \mathrm{rev})\end{array}$ & $\begin{array}{c}d \\
(\mathrm{~mm})\end{array}$ & $\begin{array}{c}R a \\
(\mu \mathrm{m})\end{array}$ & $\begin{array}{c}R z \\
(\mu \mathrm{m})\end{array}$ & $Z_{X}^{\infty}\left(10^{-}\right.$ & $\begin{array}{c}Z_{Y}^{\infty} \\
\left(10^{-9}\right)\end{array}$ & $\begin{array}{c}Z_{Z}^{\infty} \\
\left(\mathbf{1 0}^{-9}\right)\end{array}$ \\
\hline 1 & 250 & 0.15 & 1.84 & 0.99 & 6.54 & 53.5924 & 109.3987 & 21.4042 \\
\hline 2 & 250 & 0.15 & 1.00 & 1.17 & 6.89 & 7.8752 & 17.0357 & 5.1515 \\
\hline 3 & 300 & 0.20 & 1.50 & 1.51 & 8.48 & 42.6708 & 89.2838 & 49.7825 \\
\hline 4 & 200 & 0.10 & 1.50 & 0.92 & 6.09 & 7.8148 & 27.6228 & 13.7093 \\
\hline 5 & 200 & 0.10 & 0.50 & 0.88 & 5.46 & 3.8607 & 5.8549 & 3.5338 \\
\hline 6 & 200 & 0.20 & 0.50 & 1.54 & 7.70 & 5.4348 & 11.4791 & 2.4236 \\
\hline 7 & 250 & 0.07 & 1.00 & 0.91 & 5.45 & 4.1928 & 9.8487 & 6.9833 \\
\hline 8 & 250 & 0.15 & 1.00 & 1.19 & 6.60 & 17.1530 & 34.7677 & 16.7381 \\
\hline 9 & 250 & 0.23 & 1.00 & 1.66 & 9.07 & 36.5517 & 69.0667 & 32.5535 \\
\hline 10 & 334 & 0.15 & 1.00 & 1.38 & 7.77 & 16.5304 & 32.8087 & 12.7461 \\
\hline 11 & 300 & 0.10 & 0.50 & 1.15 & 6.62 & 4.9492 & 2.4375 & 7.2871 \\
\hline 12 & 250 & 0.15 & 1.00 & 1.22 & 6.56 & 8.5189 & 15.8684 & 9.9977 \\
\hline 13 & 250 & 0.15 & 1.00 & 1.30 & 6.92 & 6.1172 & 12.3708 & 5.3085 \\
\hline 14 & 250 & 0.15 & 1.00 & 1.31 & 7.11 & 9.5469 & 21.7192 & 7.8476 \\
\hline 15 & 250 & 0.15 & 0.16 & 1.21 & 6.86 & 1.7339 & 1.1779 & 1.6211 \\
\hline 16 & 300 & 0.10 & 1.50 & 1.33 & 7.50 & 9.5028 & 27.8412 & 16.1128 \\
\hline 17 & 200 & 0.20 & 1.50 & 1.64 & 8.01 & 65.8605 & 68.2716 & 43.5425 \\
\hline 18 & 300 & 0.20 & 0.50 & 1.63 & 7.82 & 2.5979 & 4.5335 & 1.3140 \\
\hline 19 & 250 & 0.15 & 1.00 & 1.32 & 7.43 & 9.1410 & 21.6563 & 7.8681 \\
\hline 20 & 166 & 0.15 & 1.00 & 1.31 & 7.17 & 6.9593 & 17.6797 & 6.4155 \\
\hline
\end{tabular}

\section{A. ANOVA and Factor Analysis}

Tables II and III show the variance analysis (ANOVA) results for $R a$ and $R z$, and I-kaz coefficients $\left(Z_{X}^{\infty}, Z_{Y}^{\infty}\right.$ and $Z_{Z}^{\infty}$ ) are shown in Tables IV, V and VI. Using RSM by Design-Expert v.11, the responses obtained were the sum of squares, df, p-value, F-value and remarks. All models use optimization design generally estimated non-linear, or quadratic process order, have significant effect on $R a, R z$, $Z_{X}^{\infty}, \quad Z_{Y}^{\infty}$ and $Z_{Z}^{\infty}$ which has probability values less than 0.05 , based on the significant statistical parameters with their respective type III. Meanwhile, the lack of fit is not significant and has good indications for fitting the models. In terms of the main factors from the cutting parameters, depth of cut and feed rate are significant, while cutting speed is not significant for $R a$ and $R z$. In statistical signal processing $\mathrm{I}-\mathrm{kaz}^{\mathrm{TM}}$ method, the probability values are significant for feed rate and depth of cut, and not significant for cutting speed even when all directions have been considered. The analysis has been performed for $95 \%$ confidence level.

From the analysis, the feed rate and the depth of cut have a greater impact on the surface roughness and I-kaz coefficient, while the cutting speed is very small but significant. This can be seen from the contribution number (F-value), the feed rate with contributions of $70.4 \%$ and $71.8 \%$, the depth of cut with contributions of $14.7 \%$ and $16.1 \%$, while the cutting speed is $0.06 \%$ and $1.77 \%$ for $R a$ and $R z$ respectively. The rest of the contribution percentages are the interaction factor effect. In the case of the I-kaz coefficients, the contribution percentage is highest for depth of cut with $37.8 \%, 53.4 \%$ and $53.7 \%$ for $Z_{X}^{\infty}, Z_{Y}^{\infty}$ and $Z_{Z}^{\infty}$ respectively.

Second highest is feed rate with $30.9 \%, 25.8 \%$ and $20.5 \%$ for $Z_{X}^{\infty}, Z_{Y}^{\infty}$ and $Z_{Z}^{\infty}$ respectively. Then, cutting speed with $0.0027 \%, 1.229 \%$ and $1.471 \%$ for $Z_{X}^{\infty}, Z_{Y}^{\infty}$ and $Z_{Z}^{\infty}$ respectively.

It can be found that the increase of the $R a$ and $R z$ values and the I-kaz coefficients caused by the increase of the depth of cut and the feed rate. The increase in feed rate causes a higher amount of cutting material in the same time unit, as well as an influence on the cutting force. However, the $R a$ and $R z$, and I-kaz coefficients decreased with an increase in cutting speed because of the reduction in the material shear strength [20]. 
Table- III: ANOVA result for $R a$

\begin{tabular}{|c|c|c|c|c|c|}
\hline Source & $\begin{array}{c}\text { Sum of } \\
\text { Squares }\end{array}$ & $\mathbf{d f}$ & $\begin{array}{c}\text { Mean } \\
\text { Square }\end{array}$ & F-Value & p-Value \\
\hline Model & 1.13 & 9 & 0.1261 & 27.37 & $<0.0001$ \\
\hline$V c$ & 0.0007 & 1 & 0.0007 & 0.1620 & 0.6958 \\
\hline$f$ & 0.8057 & 1 & 0.8057 & 174.87 & $<0.0001$ \\
\hline$d$ & 0.1686 & 1 & 0.1686 & 36.60 & 0.0001 \\
\hline$V c \times f$ & 0.0172 & 1 & 0.0172 & 3.72 & 0.0825 \\
\hline$V c \times d$ & 0.0343 & 1 & 0.0343 & 7.43 & 0.0213 \\
\hline$f \times d$ & 0.0397 & 1 & 0.0397 & 8.61 & 0.0149 \\
\hline$V c^{2}$ & 0.0230 & 1 & 0.0230 & 5.00 & 0.0494 \\
\hline$f^{2}$ & 0.0045 & 1 & 0.0045 & 0.9802 & 0.3455 \\
\hline$d^{2}$ & 0.0506 & 1 & 0.0506 & 10.98 & 0.0078 \\
\hline Residual & 0.0461 & 10 & 0.0046 & & \\
\hline Lack of Fit & 0.0259 & 5 & 0.0052 & 1.28 & 0.3951 \\
\hline Pure Error & 0.0202 & 5 & 0.0040 & & \\
\hline Cor Total & 1.18 & 19 & & & \\
\hline
\end{tabular}

Table- IV: ANOVA result for surface $R z$

\begin{tabular}{|c|c|c|c|c|c|}
\hline Source & $\begin{array}{c}\text { Sum of } \\
\text { Squares }\end{array}$ & df & $\begin{array}{c}\text { Mean } \\
\text { Square }\end{array}$ & F-Value & p-Value \\
\hline Model & 14.02 & 9 & 1.56 & 8.13 & 0.0015 \\
\hline$V c$ & 0.2490 & 1 & 0.2490 & 1.30 & 0.2810 \\
\hline$f$ & 10.10 & 1 & 10.10 & 52.68 & $<0.0001$ \\
\hline$d$ & 2.27 & 1 & 2.27 & 11.82 & 0.0064 \\
\hline$V c \times f$ & 0.0011 & 1 & 0.0011 & 0.0059 & 0.9404 \\
\hline$V c \times d$ & 0.2720 & 1 & 0.2720 & 1.42 & 0.2611 \\
\hline$f \times d$ & 0.7351 & 1 & 0.7351 & 3.83 & 0.0787 \\
\hline$V c^{2}$ & 0.3437 & 1 & 0.3437 & 1.79 & 0.2102 \\
\hline$f^{2}$ & 0.0926 & 1 & 0.0926 & 0.4833 & 0.5027 \\
\hline$d^{2}$ & 0.0048 & 1 & 0.0048 & 0.0252 & 0.8770 \\
\hline Residual & 1.92 & 10 & 0.1917 & & \\
\hline Lack of Fit & 1.39 & 5 & 0.2776 & 2.62 & 0.1567 \\
\hline Pure Error & 0.5291 & 5 & 0.1058 & & \\
\hline Cor Total & 15.94 & 19 & & & \\
\hline \multicolumn{7}{|r|}{}
\end{tabular}

Table- V: ANOVA result for $Z_{X}^{\infty}$

\begin{tabular}{|c|c|c|c|c|c|}
\hline Source & $\begin{array}{c}\text { Sum of } \\
\text { Squares }\end{array}$ & df & $\begin{array}{c}\text { Mean } \\
\text { Square }\end{array}$ & F-Value & p-Value \\
\hline Model & $4.459 \mathrm{E}-15$ & 9 & $4.954 \mathrm{E}-16$ & 23.28 & $<0.0001$ \\
\hline$V c$ & $1.237 \mathrm{E}-19$ & 1 & $1.237 \mathrm{E}-19$ & 0.0058 & 0.9407 \\
\hline$f$ & $1.388 \mathrm{E}-15$ & 1 & $1.388 \mathrm{E}-15$ & 65.23 & $<0.0001$ \\
\hline$d$ & $1.698 \mathrm{E}-15$ & 1 & $1.698 \mathrm{E}-15$ & 79.80 & $<0.0001$ \\
\hline$V c \times f$ & $7.541 \mathrm{E}-17$ & 1 & $7.541 \mathrm{E}-17$ & 3.54 & 0.0891 \\
\hline$V c \times d$ & $3.523 \mathrm{E}-17$ & 1 & $3.523 \mathrm{E}-17$ & 1.66 & 0.2272 \\
\hline$f \times d$ & $9.625 \mathrm{E}-16$ & 1 & $9.625 \mathrm{E}-16$ & 45.23 & $<0.0001$ \\
\hline$V c^{2}$ & $1.082 \mathrm{E}-17$ & 1 & $1.082 \mathrm{E}-17$ & 0.5083 & 0.4922 \\
\hline$f^{2}$ & $2.211 \mathrm{E}-16$ & 1 & $2.211 \mathrm{E}-16$ & 10.39 & 0.0091 \\
\hline$d^{2}$ & $1.045 \mathrm{E}-16$ & 1 & $1.045 \mathrm{E}-16$ & 4.91 & 0.0511 \\
\hline Residual & $3.183 \mathrm{e}-16$ & 10 & $3.183 \mathrm{e}-17$ & & \\
\hline Lack of Fit & $2.448 \mathrm{e}-16$ & 5 & $4.897 \mathrm{e}-17$ & 3.33 & 0.1062 \\
\hline Pure Error & $7.344 \mathrm{e}-17$ & 5 & $1.469 \mathrm{e}-17$ & & \\
\hline Cor Total & $6.553 \mathrm{e}-15$ & 19 & & & \\
\hline
\end{tabular}

Table- VI: ANOVA result for $Z_{Y}^{\infty}$

\begin{tabular}{|c|c|c|c|c|c|}
\hline Source & $\begin{array}{c}\text { Sum of } \\
\text { Squares }\end{array}$ & $\mathbf{d f}$ & $\begin{array}{c}\text { Mean } \\
\text { Square }\end{array}$ & F-Value & p-Value \\
\hline Model & $1.182 \mathrm{E}-14$ & 9 & $1.313 \mathrm{E}-15$ & 24.67 & $<0.0001$ \\
\hline$V c$ & $1.466 \mathrm{E}-16$ & 1 & $1.466 \mathrm{E}-16$ & 2.75 & 0.1281 \\
\hline$f$ & $3.070 \mathrm{E}-15$ & 1 & $3.070 \mathrm{E}-15$ & 57.66 & $<0.0001$ \\
\hline$d$ & $6.356 \mathrm{E}-15$ & 1 & $6.356 \mathrm{E}-15$ & 119.38 & $<0.0001$ \\
\hline$V c \times f$ & $3.609 \mathrm{E}-18$ & 1 & $3.609 \mathrm{E}-18$ & 0.0678 & 0.7999 \\
\hline$V c \times d$ & $3.165 \mathrm{E}-17$ & 1 & $3.165 \mathrm{E}-17$ & 0.5945 & 0.4585 \\
\hline$f \times d$ & $1.412 \mathrm{E}-15$ & 1 & $1.412 \mathrm{E}-15$ & 26.51 & 0.0004 \\
\hline$V c^{2}$ & $1.683 \mathrm{E}-17$ & 1 & $1.683 \mathrm{E}-17$ & 0.3161 & 0.5864 \\
\hline$f^{2}$ & $5.373 \mathrm{E}-16$ & 1 & $5.373 \mathrm{E}-16$ & 10.09 & 0.0099 \\
\hline$d^{2}$ & $3.409 \mathrm{E}-16$ & 1 & $3.409 \mathrm{E}-16$ & 6.40 & 0.0298 \\
\hline Residual & $5.324 \mathrm{E}-16$ & 10 & $5.324 \mathrm{E}-17$ & & \\
\hline $\begin{array}{c}\text { Lack of } \\
\text { Fit }\end{array}$ & $2.265 \mathrm{E}-16$ & 5 & $4.530 \mathrm{E}-17$ & 0.7405 & 0.6252 \\
\hline $\begin{array}{c}\text { Pure } \\
\text { Error }\end{array}$ & $3.059 \mathrm{E}-16$ & 5 & $6.118 \mathrm{E}-17$ & & \\
\hline Cor & $1.235 \mathrm{E}-14$ & 19 & & & \\
\hline
\end{tabular}

\begin{tabular}{|l|l|l|l|l|l|}
\hline Total & & & & & \\
\hline
\end{tabular}

Table- VII: ANOVA result for $Z_{Z}^{\infty}$

\begin{tabular}{|c|c|c|c|c|c|}
\hline Source & $\begin{array}{c}\text { Sum of } \\
\text { Squares }\end{array}$ & df & $\begin{array}{c}\text { Mean } \\
\text { Square }\end{array}$ & F-Value & p-Value \\
\hline Model & $3.286 \mathrm{E}-15$ & 9 & $3.651 \mathrm{E}-16$ & 21.88 & $<0.0001$ \\
\hline$V c$ & $4.867 \mathrm{E}-17$ & 1 & $4.867 \mathrm{E}-17$ & 2.92 & 0.1185 \\
\hline$f$ & $6.795 \mathrm{E}-16$ & 1 & $6.795 \mathrm{E}-16$ & 40.72 & $<0.0001$ \\
\hline$d$ & $1.778 \mathrm{E}-15$ & 1 & $1.778 \mathrm{E}-15$ & 106.57 & $<0.0001$ \\
\hline$V c \times f$ & $1.484 \mathrm{E}-17$ & 1 & $1.484 \mathrm{E}-17$ & 0.8894 & 0.3679 \\
\hline$V c \times d$ & $3.684 \mathrm{E}-17$ & 1 & $3.684 \mathrm{E}-17$ & 2.21 & 0.1681 \\
\hline$f \times d$ & $4.302 \mathrm{E}-16$ & 1 & $4.302 \mathrm{E}-16$ & 25.78 & 0.0005 \\
\hline$V c^{2}$ & $1.546 \mathrm{E}-18$ & 1 & $1.546 \mathrm{E}-18$ & 0.0926 & 0.7671 \\
\hline$f^{2}$ & $2.225 \mathrm{E}-16$ & 1 & $2.225 \mathrm{E}-16$ & 13.34 & 0.0044 \\
\hline$d^{2}$ & $1.005 \mathrm{E}-16$ & 1 & $1.005 \mathrm{E}-16$ & 6.02 & 0.0340 \\
\hline Residual & $1.669 \mathrm{E}-16$ & 10 & $1.669 \mathrm{E}-17$ & & \\
\hline Lack of Fit & $7.515 \mathrm{E}-17$ & 5 & $1.503 \mathrm{E}-17$ & 0.8193 & 0.5839 \\
\hline Pure Error & $9.172 \mathrm{E}-17$ & 5 & $1.834 \mathrm{E}-17$ & & \\
\hline Cor Total & $3.453 \mathrm{E}-15$ & 19 & & & \\
\hline
\end{tabular}

\section{B. Multiple Regression Equations}

The factor-response relationship was based on quadratic regression equations. The obtained multiple equations of regression were shown follows.

The final equation of regression in terms of $R a$ and $R z$ models with coefficient of determination, $R^{2} 96.1 \%$ and $87.98 \%$ respectively, are given in (15) and (16).

$$
\begin{aligned}
& R a=0.04245-0.003296 V_{c}+ \\
& 11.43133 f+0.532218 d-0.03535 V_{c} f \\
& -0.000385 V_{c} d-1.135 f d+0.00002 V_{c}^{2} \\
& +11.32303 f^{2}-0.144864 d^{2} \\
& R z=5.08795-0.02391 V_{c}+ \\
& 29.81226 f+0.467409 d-0.099 V_{c} f \\
& +0.003 V_{c} d-2.7 f d+0.000082 V_{c}^{2} \\
& +52.7942 f^{2}-0.264018 d^{2}
\end{aligned}
$$

The $I-k a z_{X}, I-k a z_{Y}$ and $I-k a z_{Z}$ coefficient models are given in (17), (18) and (19) with $R^{2}$ is $95.44 \%, 95.69 \%$ and $95.17 \%$ respectively.

$$
\begin{aligned}
& Z_{X}^{\infty}=-8.91964 \times 10^{-9}+3.38525 \times 10^{-10} V c \\
& -2.27312 \times 10^{-7} f-6.93714 \times 10^{-8} d \\
& -1.56782 \times 10^{-9} V c f-1.11533 \times 10^{-10} V c d \\
& +4.72723 \times 10^{-7} f d-1.20712 \times 10^{-14} V c^{2} \\
& +1.20808 \times 10^{-6} f^{2}+2.69364 \times 10^{-8} d^{2} \\
& Z_{Y}^{\infty}=1.01591 \times 10^{-7}-3.85178 \times 10^{-11} V c \\
& -8.57117 \times 10^{-7} f-1.36127 \times 10^{-7} d \\
& +6.60895 \times 10^{-10} V c f+1.37725 \times 10^{-10} V c d \\
& +4.92099 \times 10^{-7} f d-3.02181 \times 10^{-13} V c^{2} \\
& +1.70796 \times 10^{-6} f^{2}+4.10986 \times 10^{-8} d^{2}
\end{aligned}
$$

Published By:

Blue Eyes Intelligence Engineering

\& Sciences Publication 


$$
\begin{aligned}
& Z_{Z}^{\infty}=8.29624 \times 10^{-8}-1.21475 \times 10^{-10} V c \\
& -7.01669 \times 10^{-7} f-6.17282 \times 10^{-8} d \\
& -1.33295 \times 10^{-10} V c f+2.18065 \times 10^{-11} V c d \\
& +3.61131 \times 10^{-7} f d+2.98768 \times 10^{-13} V c^{2} \\
& +1.73955 \times 10^{-6} f^{2}+1.06945 \times 10^{-8} d^{2}
\end{aligned}
$$

In (15) to (19) can be applied to model and predict the values of the surface roughness and I-kaz coefficients. Fig. 4 shows the comparison between measured and predicted responses for surface roughness $R a$ and $R z$ for all experimental runs. Fig. 5 shows the comparison between measured and predicted responses for $Z_{X}^{\infty}, Z_{Y}^{\infty}$ and $Z_{Z}^{\infty}$ for all experimental runs.

\section{Optimization of Cutting Conditions}

The criteria of the cutting parameters, surface roughness and I-kaz coefficients $\left(Z_{X}^{\infty}, Z_{Y}^{\infty}\right.$ and $Z_{Z}^{\infty}$ ) were constrained based on in ranges for cutting speed, feed rate and depth of cut, minimize the values of $R a$ and $R z$ and I-kaz coefficients. Table VIII shows the criteria and goals for cutting conditions. The optimal setting of cutting parameters is observed at $200 \mathrm{~m} / \mathrm{min}, 0.1 \mathrm{~mm} / \mathrm{rev}$ and $0.521 \mathrm{~mm}$ for cutting speed, feed rate and depth of cut respectively as

\begin{tabular}{|c|c|c|c|}
\hline Feed rate, $f$ & in range & 0.1 & 0.2 \\
\hline Depth of cut, $d$ & in range & 0.5 & 1.5 \\
\hline$R a$ & minimize & 0.88 & 1.657 \\
\hline$R z$ & minimize & 5.45 & 9.07 \\
\hline $\mathrm{I}-\mathrm{kaz}_{\mathrm{x}}^{\mathrm{TM}}$ & minimize & 2.5979E-09 & $6.8410 \mathrm{E}-08$ \\
\hline 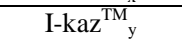 & minimize & $2.4375 \mathrm{E}-09$ & $1.0940 \mathrm{E}-07$ \\
\hline $\mathrm{I}-\mathrm{kaz}_{\mathrm{z}}^{\mathrm{TM}}$ & minimize & 1.3140E-09 & 4.9783E-08 \\
\hline
\end{tabular}
shown in Table XI.

Table- VIII: Criteria and goals for the condition of cutting.

\begin{tabular}{|c|c|c|c|}
\hline Criteria & Goal & Lower Limit & Upper Limit \\
\hline Cutting speed, $V c$ & in range & 200 & 300 \\
\hline
\end{tabular}

\section{Validation of Experiments}

Table- IX and Table $\mathrm{X}$ demonstrate the validation experiment and their contrast with the expected model for surface roughness and I-kaz coefficients. For surface roughness and I-kaz coefficients, the three conformation experiments were conducted. The analysis of Tables IX and $\mathrm{X}$ indicates that the calculated errors are small. In comparison, the errors between predicted and experimental values for $R a, R z, Z_{X}^{\infty}, Z_{Y}^{\infty}$ and $Z_{Z}^{\infty}$ were within -1.78 to $8.83,-3.47$ to $-5.19,2.99$ to $10.22,2.65$ to 4.43 and -9.82 to 9.75 respectively. In this experiment, $95 \%$ prediction interval was applied for the confidence level. Thus, the model accurately obtained as the comparison between predicted and measured data, and errors of mean relative percentages shown in Fig. 6(a), Fig. 6(b) and Fig. 6(c). Fig. 7(a) and Fig. 7(b) show the effect of feed rate and cutting speed on $R a, R z, Z_{X}^{\infty}, Z_{Y}^{\infty}$ and $Z_{Z}^{\infty}$. The predicted response surface plane generally cuts through the middle of the design points. The depth of cut and feed rate show a significant effect on $R a, R z, Z_{X}^{\infty}, Z_{Y}^{\infty}$ and $Z_{Z}^{\infty}$.

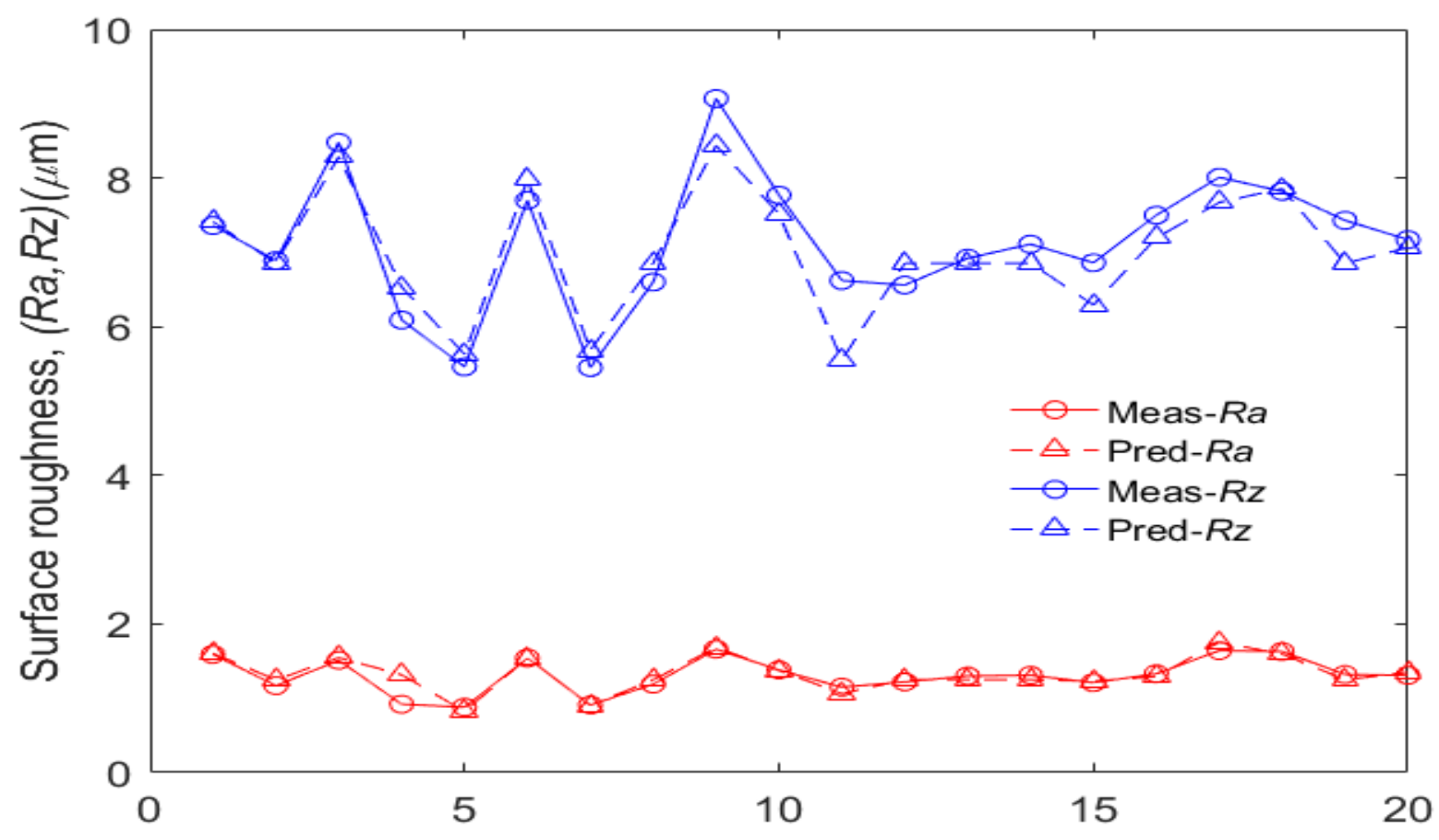

Experimental Run No.

Fig. 4. Predicted and measured surface roughness values 


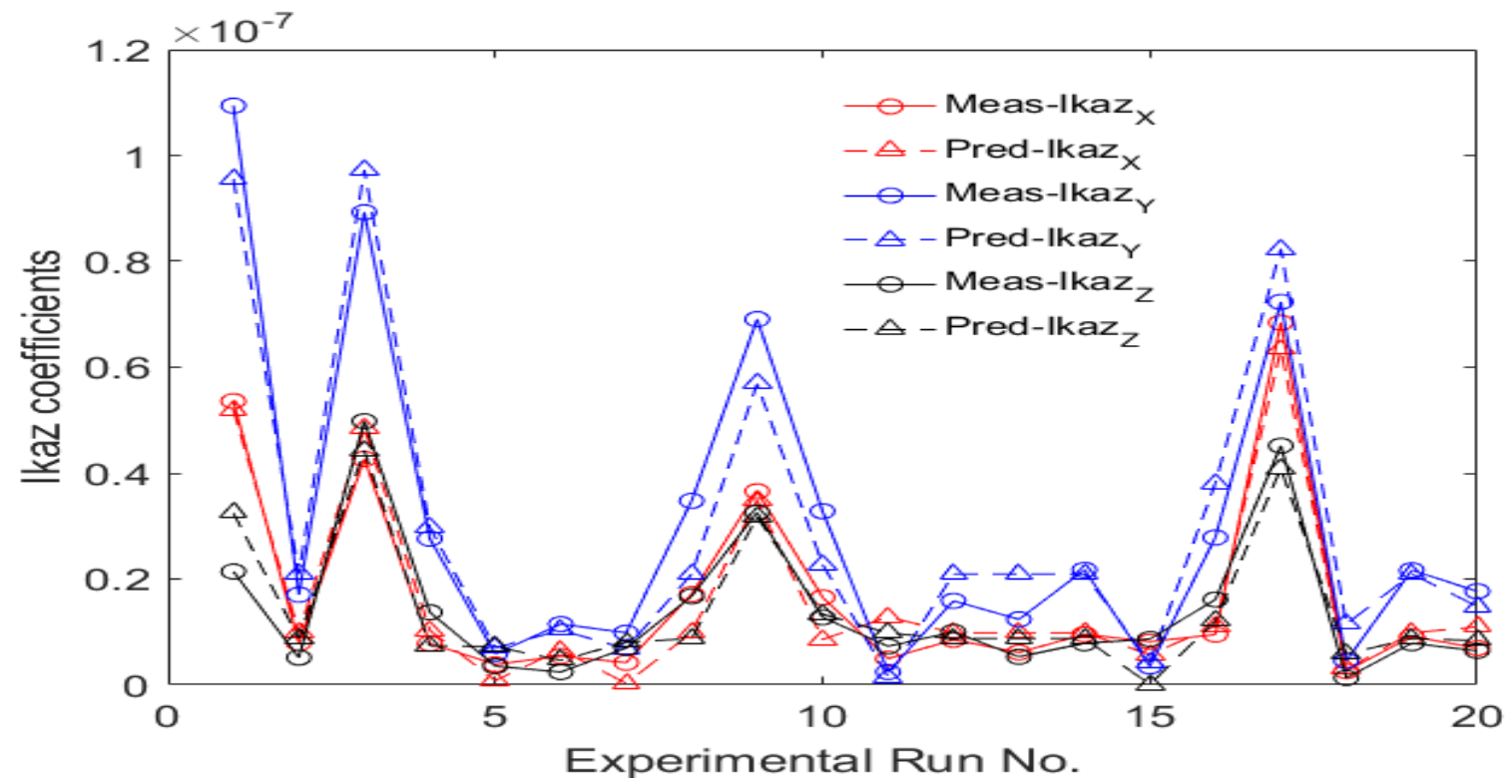

Fig. 5. Predicted and measured I-kaz coefficients

Table- IX: Confirmation experiments for surface roughness values

\begin{tabular}{|c|c|c|c|c|c|c|c|c|c|}
\hline No. & $\boldsymbol{V c}$ & $\boldsymbol{f}$ & $\boldsymbol{d}$ & \multicolumn{6}{|c|}{ Surface Roughness } \\
\hline & $(\boldsymbol{m} / \mathbf{m i n})$ & $(\boldsymbol{m} / \mathbf{r e v})$ & $(\boldsymbol{m m})$ & \multicolumn{3}{c|}{$\boldsymbol{R a}(\boldsymbol{\mu m})$} & \multicolumn{3}{c|}{$\boldsymbol{R z}(\boldsymbol{\mu m})$} \\
\hline & & & & Actual & Pred & Error $(\boldsymbol{\%})$ & Actual & Pred & Error (\%) \\
\hline 1 & 210 & 0.12 & 0.75 & 1.118 & 1.019 & 8.83 & 5.90 & 6.21 & -5.19 \\
\hline 2 & 225 & 0.15 & 0.75 & 1.225 & 1.198 & 2.17 & 7.15 & 6.742 & 5.69 \\
\hline 3 & 200 & 0.12 & 0.6 & 1.016 & 0.997 & -1.78 & 5.67 & 5.867 & -3.47 \\
\hline
\end{tabular}

Table- X: Confirmation experiments for I-kaz coefficients

\begin{tabular}{|c|c|c|c|c|c|c|c|c|c|c|c|c|}
\hline \multirow[t]{3}{*}{ No. } & \multirow{3}{*}{$\begin{array}{c}V c \\
(\mathrm{~m} / \mathrm{min})\end{array}$} & \multirow{3}{*}{$\begin{array}{c}f \\
(m / r e v)\end{array}$} & \multirow{3}{*}{$\begin{array}{c}d \\
(\mathrm{~mm})\end{array}$} & \multicolumn{9}{|c|}{ I-kaz Coefficient $\left(Z^{\infty}\right)$} \\
\hline & & & & \multicolumn{3}{|c|}{$Z_{X}^{\infty}$} & \multicolumn{3}{|c|}{$\mathbf{Z}_{Y}^{\infty}$} & \multicolumn{3}{|c|}{$Z_{Z}^{\infty}$} \\
\hline & & & & $\begin{array}{c}\text { Actual } \\
\left.(\mathbf{x 1 0})^{9}\right)\end{array}$ & $\begin{array}{l}\text { Pred } \\
\left(\mathbf{x 1 0}^{9}\right)\end{array}$ & $\begin{array}{c}\text { Error } \\
(\%)\end{array}$ & $\begin{array}{c}\text { Actual } \\
\left.(\mathbf{x 1 0})^{9}\right)\end{array}$ & $\begin{array}{c}\text { Pred } \\
\left(\mathbf{x 1 0}^{9}\right)\end{array}$ & Error $(\%)$ & $\begin{array}{c}\text { Actual } \\
\left(\mathbf{x 1 0}^{9}\right)\end{array}$ & $\begin{array}{c}\text { Pred } \\
\left.(\mathbf{x 1 0})^{9}\right)\end{array}$ & $\begin{array}{c}\text { Error } \\
(\%)\end{array}$ \\
\hline 1 & 210 & 0.12 & 0.75 & 4.5520 & 4.4160 & 2.99 & 7.6651 & 7.4622 & 2.65 & 3.7208 & 3.3581 & 9.75 \\
\hline 2 & 225 & 0.15 & 0.75 & 4.9504 & 4.4443 & 10.22 & 0.1069 & 0.1022 & 4.43 & 3.1312 & 3.4388 & -9.82 \\
\hline 3 & 200 & 0.12 & 0.6 & 3.4810 & 3.1865 & 8.46 & 5.3169 & 5.1196 & 3.71 & 1.5662 & 1.6215 & -3.53 \\
\hline
\end{tabular}
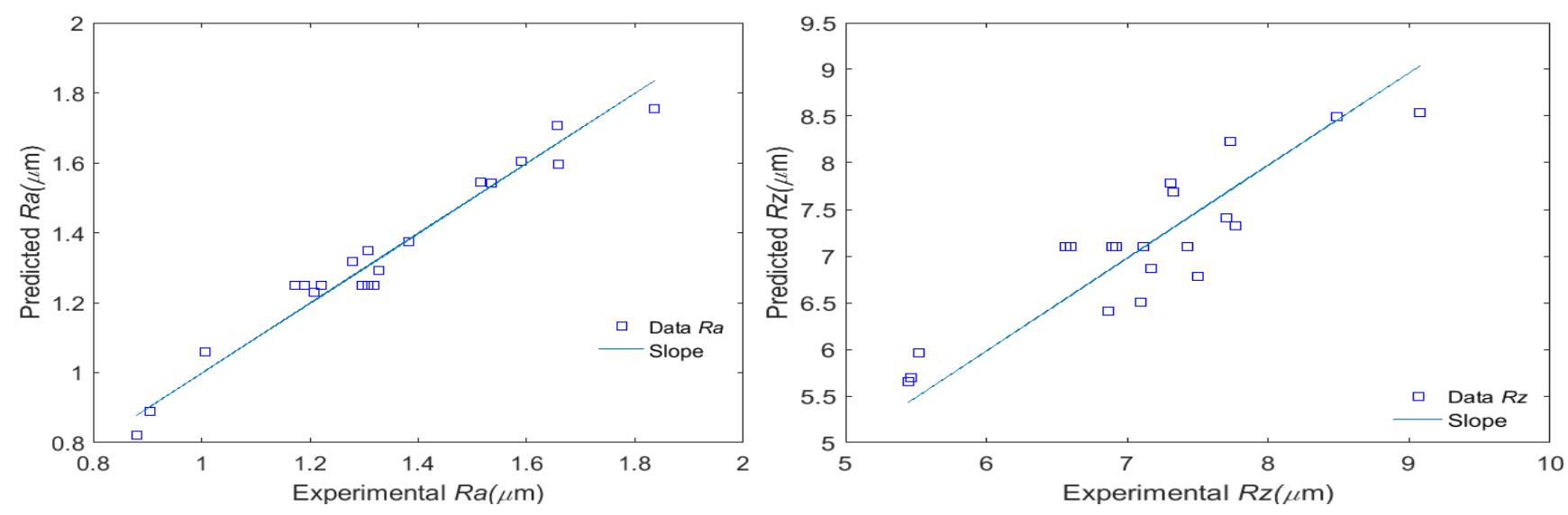

Fig. 6(a). Comparison between measured and prediction data for $\mathrm{Ra}$ and $\mathrm{Rz}$ 

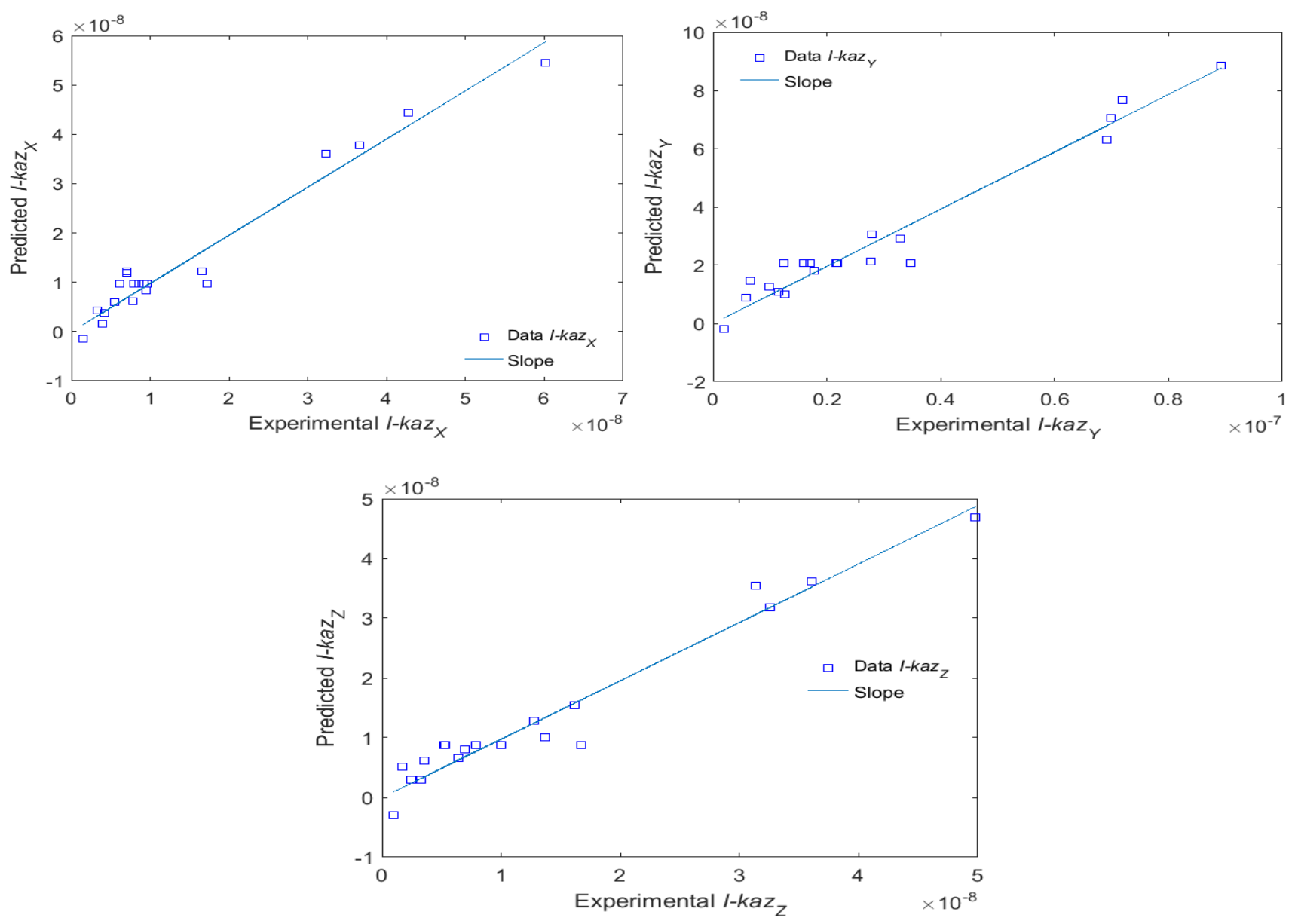

Fig. 6(b). Comparison between measured and prediction data $Z_{X}^{\infty}, Z_{Y}^{\infty}$ and $Z_{Z}^{\infty}$

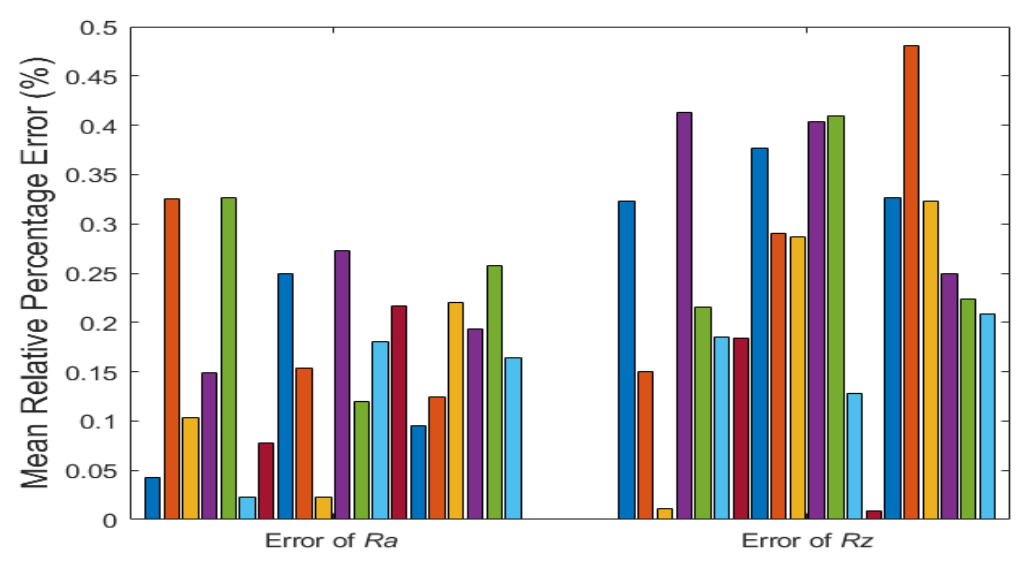

Fig. 6(c). Mean relative percentage error for $\mathrm{Ra}$ and $\mathrm{Rz}$ 

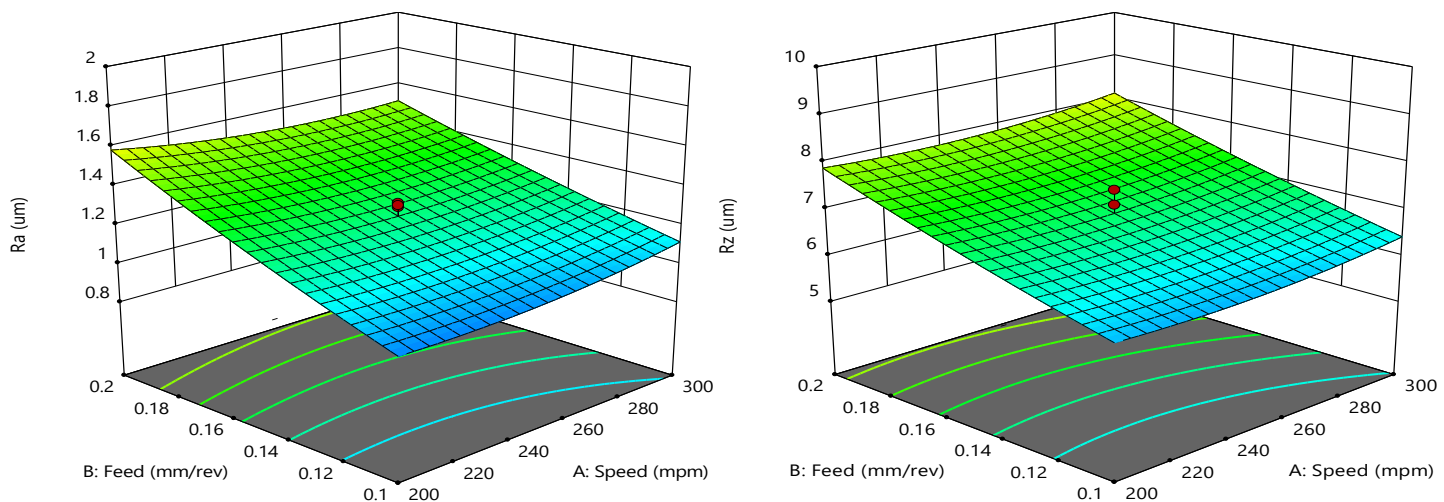

Fig. 7(a). Influence of feed rate and cutting speed on Ra and Rz
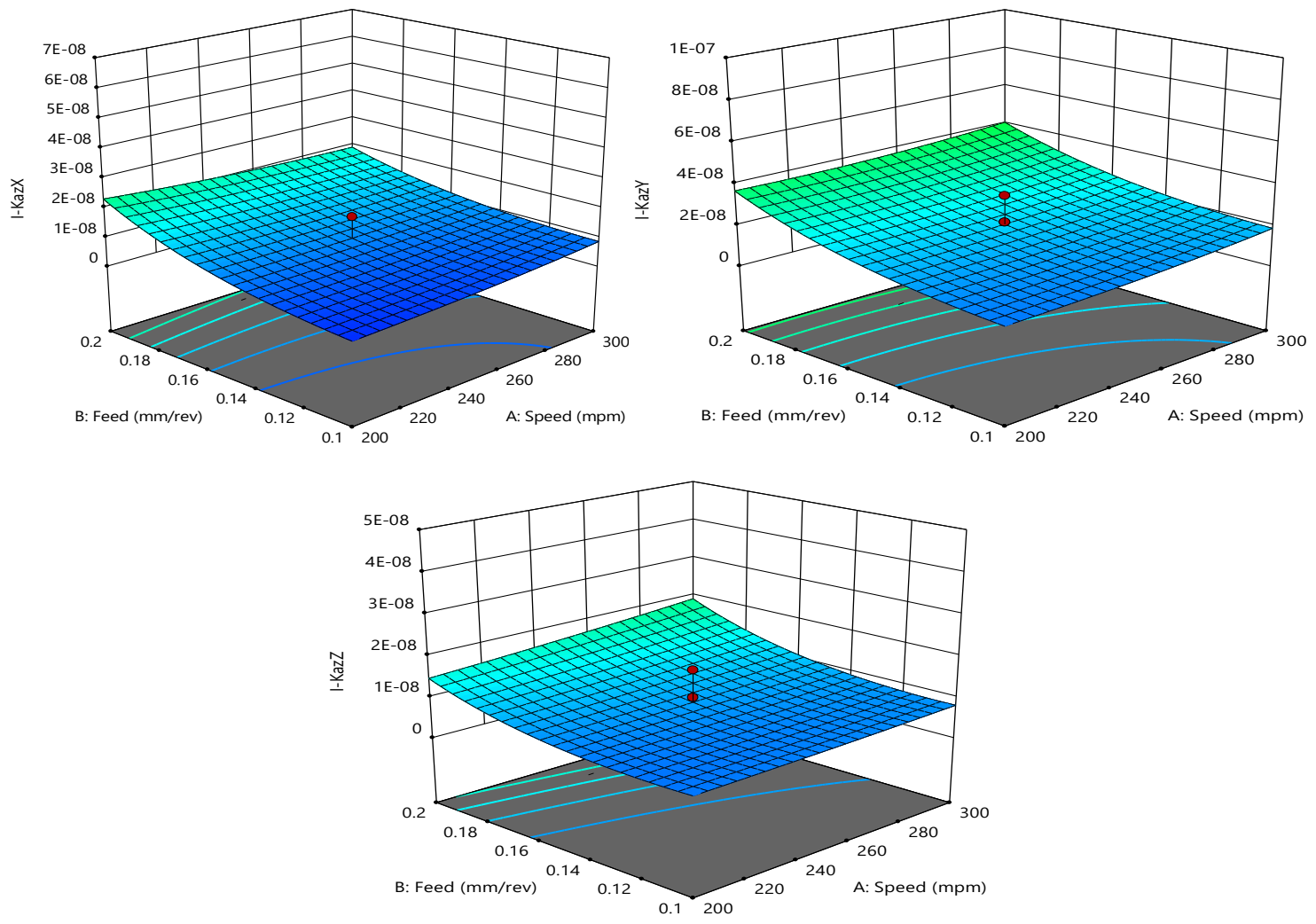

Fig. 7(b). Influence of feed rate and cutting speed on $Z_{X}^{\infty}, Z_{Y}^{\infty}$ and $Z_{Z}^{\infty}$

Table- XI: Optimization of the responses for surface roughness values and I-kaz ${ }^{\mathrm{TM}}$ coefficients

\begin{tabular}{|c|c|c|c|c|c|c|c|c|c|}
\hline \multirow[t]{2}{*}{$\begin{array}{l}\text { Test } \\
\text { No. }\end{array}$} & \multirow[t]{2}{*}{$\begin{array}{c}V c \\
(\mathbf{m} / \mathbf{m i n})\end{array}$} & \multirow{2}{*}{$\begin{array}{c}f \\
(\mathbf{m m} / \mathrm{rev} \\
)\end{array}$} & \multirow[t]{2}{*}{$\begin{array}{c}d \\
(\mathbf{m m})\end{array}$} & \multicolumn{2}{|c|}{$\begin{array}{c}\text { Surface } \\
\text { Roughness }\end{array}$} & \multicolumn{3}{|c|}{ I-kaz Coefficients $\left(Z^{\infty}\right)$} & \multirow[t]{2}{*}{$\begin{array}{c}\text { Desirabilit } \\
\mathbf{y} \\
\end{array}$} \\
\hline & & & & $R a$ & $R z$ & $Z_{X}^{\infty}$ & $Z_{Y}^{\infty}$ & $Z_{Z}^{\infty}$ & \\
\hline 1 & 200.001 & 0.100 & 0.521 & 0.881 & 5.603 & $4.654 \mathrm{E}-08$ & $6.602 \mathrm{E}-09$ & $7.006 \mathrm{E}-08$ & 0.959 \\
\hline 2 & 200.005 & 0.100 & 0.558 & 0.888 & 5.622 & $9.951 \mathrm{E}-11$ & 6.049E-09 & $6.648 \mathrm{E}-08$ & 0.959 \\
\hline 3 & 200.012 & 0.100 & 0.503 & 0.880 & 5.602 & $7.461 \mathrm{E}-10$ & $6.856 \mathrm{E}-09$ & 7.104E-09 & 0.958 \\
\hline 4 & 207.049 & 0.100 & 0.505 & 0.886 & 5.607 & $1.597 \mathrm{E}-09$ & $6.709 \mathrm{E}-09$ & 7.164E-09 & 0.957 \\
\hline 5 & 207.748 & 0.100 & 0.500 & 0.886 & 5.606 & $1.765 \mathrm{E}-09$ & $6.767 \mathrm{E}-09$ & $7.211 \mathrm{E}-09$ & 0.956 \\
\hline 6 & 209.695 & 0.100 & 0.530 & 0.894 & 5.628 & $1.471 \mathrm{E}-09$ & $6.241 \mathrm{E}-09$ & $6.914 \mathrm{E}-09$ & 0.955 \\
\hline 7 & 210.963 & 0.100 & 0.582 & 0.909 & 5.672 & $7.799 \mathrm{E}-10$ & $5.516 \mathrm{E}-09$ & $6.328 \mathrm{E}-09$ & 0.953 \\
\hline 8 & 225.000 & 0.100 & 0.568 & 0.928 & 5.716 & $2.597 \mathrm{E}-09$ & 5.357E-09 & $6.674 \mathrm{E}-09$ & 0.945 \\
\hline
\end{tabular}

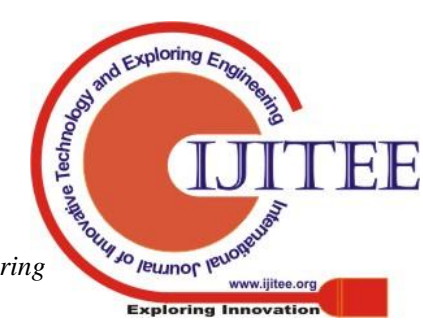




\section{RESEARCH AND MODELLING OF SURFACE ROUGHNESS, CUTTING FORCES AND I-KAZ COEFFICIENTS FOR S42C IN TURNING USING RESPONSE SURFACE METHODOLOGY}

\section{CONCLUSION}

This research presents the optimization of cutting parameters in turning process based on the surface roughness, the cutting forces and I-kaz coefficients of the S45C mild steel. The following conclusion can be drawn:

The comparison between the predicted and measured surface roughness values of $R a$ and $R z$ and the Ikaz coefficients reveals that strong agreement has been reached. The model can therefore be used to predict surface roughness and I-kaz coefficients.

- The surface roughness is strongly affected by the feed rate $(70.4121 \%$ for $R a$ and $71.8157 \%$ for $R z)$ and followed by depth of cut $(14.7371 \%$ for $R a$ and $16.1136 \%$ for $R z$ ).

- The I-kaz coefficients are strongly affected by the depth of cut $\left(37.7708 \%\right.$ for $Z_{X}^{\infty}, 53.3498 \%$ for $Z_{Y}^{\infty}$ and $53.6763 \%$ for $\left.Z_{Z}^{\infty}\right)$ and followed by feed rate $(30.8746 \%$ for $Z_{X}^{\infty}$ and $25.7677 \%$ for $Z_{Y}^{\infty}$ and $20.5095 \%$ for $Z_{Z}^{\infty}$.

- The optimal configuration of cutting parameters is observed at a cutting speed of $200 \mathrm{~m} / \mathrm{min}$, a depth of cut of $0.521 \mathrm{~mm}$ and a feed rate of $0.1 \mathrm{~mm} / \mathrm{rev}$ with $95.9 \%$ desirability.

The experimental investigation in this paper verified that the optimization models can be used for turning S45C steel.

\section{ACKNOWLEDGMENT}

We would like to thank Universiti Putra Malaysia for their support (Geran Putra: 9564400).

\section{REFERENCES}

1. G. D. O. Urbikain, L. N. L. Lacalle, and A. E. Zúñiga. "Spindle speed variation technique in turning operations: Modeling and real implementation," Journal of Sound and Vibration, 383, 2016, pp. 384-396.

2. E. Budak, and L. T. Tunc, "Identification and modeling of process damping in turning and milling using a new approach," CIRP annals 59, no. 1, 2010, pp. 403-408.

3. O. Gutnichenko, A. Agic, and J-E. Ståhl, "Modeling of force build-up process and optimization of tool geometry when intermittent turning," Procedia CIRP, 58, 2017, pp. 393-398.

4. A. P. Longstaff, S. Fletcher, S. Parkinson, and A. Myers, "The role of measurement and modelling of machine tools in improving product quality," International Journal of Metrology and Quality Engineering, 4, no. 3, 2013, pp. 177-184.

5. A. K. Parida, and K. Maity, "Modeling of machining parameters affecting flank wear and surface roughness in hot turning of Monel-400 using response surface methodology (RSM)," Measurement, 137, 2019, pp. 375 381.

6. K. Bouacha, M. A. Yallese, T. Mabrouki, and J. -F Rigal, "Statistical analysis of surface roughness and cutting forces using response surface methodology in hard turning of AISI 52100 bearing steel with CBN tool,

" International Journal of Refractory Metals and Hard Materials, 28, no. 3, 2010, pp. 349-361.

7. D. P. Selvaraj, P. Chandramohan, and M. Mohanraj, "Optimization of surface roughness, cutting force and tool wear of nitrogen alloyed duplex stainless steel in a dry turning process using Taguchi method," Measurement, 49, 2014, pp. 205-215.
8. M. S. Said, J. A. Ghani, R. Othman, M. A. Selamat, N N. Wan, and C. H. Che Hassan, "Surface roughness and chip formation of AlSi/AIN metal matrix composite by end milling machining using the Taguchi method," Jurnal Teknologi, 68, no. 4, 2014, pp. 13-17.

9. M. S. Ruslan, K. Othman, J. A. Ghani, M. S. Kassim, and C. H. Che Haron, "Surface roughness of magnesium alloy AZ91D in high speed milling," Jurnal Teknologi 78, no. 6-9, 2016, pp. 115-119.

10. H. Azmi, C. H. Che Haron, J. A. Ghani, M. Suhaily, A B. Sanuddin, and J. H. Song, "Study on machinability effect of surface roughness in milling kenaf fiber reinforced plastic composite (unidirectional) using response surface methodology," ARPN J Eng Appl Sci, 11, 2016, pp. 4761-4766.

11. R. Samin, M. Z. Nuawi, S. M. Haris, and J. A. Ghani, "Stability analysis of regenerative vibration in turning operation using I-kaz3D signal processing approach," Journal of Physics: Conference Series, 1262, no. 1, pp. 1 9. 2019.

12. M. Wang, L. Gao, and Y. Zheng, "An examination of the fundamental mechanics of cutting force coefficients," International Journal of Machine Tools and Manufacture, 78, 2014, pp. 1-7.

13. X. Wang, T. Shi, G. Liao, Y. Zhang, Y. Hong, and K Chen, "Using wavelet packet transform for surface roughness evaluation and texture extraction," Sensors, 17, no. 4, 2017, pp. 1-12.

14. P. Borghesani, W. A. Smith, X. Zhang, P. Feng, J. Antoni, and Z. Peng, "A new statistical model for acoustic emission signals generated from sliding contact in machine elements," Tribology International, 127, 2018, pp. 412-419.

15. D. N. Joanes, and C. A. Gill, "Comparing measures of sample skewness and kurtosis," Journal of the Royal Statistical Society: Series D (The Statistician), 47, no. 1, 1998, pp. 183-189.

16. M. Z. Nuawi, M. J. M. Nor, N. Jamaludin, S. Abdullah, F. Lamin, and C. K. E. Nizwan, "Development of integrated kurtosis-based algorithm for $z$-filter technique," Journal of Applied Sciences, 8, no. 8, 2008, pp. 1541-1547.

17. R. Samin, M. Z. Nuawi, S. M. Haris, and J. A. Ghani, "Correlation between chatter stability and integrated kurtosis-based algorithm for Z-filter (I-kazTM) coefficient in turning processes," Materials Today: Proceedings, 16, 2019, pp. 2128-2134.

18. N. Badroush, C. H. Che Haron, J. A. Ghani, M. F. Azhar, and N. H. A. Halim, "Performance of Coated Carbide Tools when Turning Inconel Alloy 718 under Cryogenic Condition using RSM," Journal of Mechanical Engineering, 5, no. 3, 2018, pp. 73-87.

19. S. Kumar, and B. Singh, "Prediction of tool chatter in turning using RSM and ANN," Materials Today: Proceedings, 5, no. 11, 2018, pp. 23806-23815.

20. H.Aouici, H. Bouchelaghem, M. A. Yallese, M. Elbah, and B. Fnides, "Machinability investigation in hard turning of AISI D3 cold work steel with ceramic tool using response surface methodology," International Journal of Advanced Manufacturing Technology, 73, no. 9-12, 2014, pp. 1775-1788.

21. S. Chinchanikar, and S. K. Choudhury, "Effect of work material hardness and cutting parameters on performance of coated carbide tool when turning hardened steel: An optimization approach," Measurement, 46, no. 4, 2013 , pp. 1572-1584. 


\section{AUTHORS PROFILE}

Razali Samin received his BEng (Hons) in Mechanical and Systems in 1996 and MSc in Robotics in 2002 from Universiti Putra Malaysia. He is currently a $\mathrm{PhD}$ student at Universiti Kebangsaan Malaysia and Senior Lecturer at Universiti Putra Malaysia. His current research interests include structural dynamics, machining dynamics, dynamics and control, robotics and automation, project risk and management

Mohd Zaki Nuawi is an Associated Professor at Universiti Kebangsaan Malaysis. He received a $\mathrm{BSc}$ (Hons) Industrial Engineering and MSc in Industrial Engineering from University in France, and $\mathrm{PhD}$ from Universiti Kebangsaan Malaysia. His current research includes acoustic and vibration, conditioned-based monitoring, applied ultrasonic and signal analysis.

Sallehuddin Mohamed Haris is an Associated Professor at Universiti Kebangsaan Malaysia. $\mathrm{He}$ received his BEng in Manufacturing Systems Engineering from the University of Leeds, UK in 1993 MSc in Mechatronics from the University of London (King's College London) in 1996 and $\mathrm{PhD}$ in Electronics and Electrical Engineering from the University of Southampton, UK in 2006. His current research interests include adaptive and switching control systems, hybrid dynamic systems, and mechatronic systems for automotive and robotic applications.

Jaharah A. Ghani is a Professor at Universiti Kebangsaan Malaysia. She received her Beng (Hons) Manufacturing System Engineering from Leeds Polytechnic, Leeds, UK, in 1991, MSc Manufacturing System Engineering from Warwick University, UK in 1992 and $\mathrm{PhD}$ from University of Malaya, Malaysia in 2005. Her research interests include metal cutting, manufacturing process and system. 